\title{
Quiet Eye: The next generation - comment on Vickers
}

\author{
Jörg Schorer ${ }^{1, *}$ Judith Tirp ${ }^{1} \&$ Rebecca Rienhoff \\ 1 Institute of Sport Science, University of Oldenburg, Oldenburg, Germany \\ 2 Institute of Sport Science, University of Muenster, Münster, Germany \\ * Corresponding author: Department of Sport Science, University of Oldenburg, Ammerländer Heerstraße 114-118, D-26127 Oldenburg, \\ Germany, Tel: +49 441 7983174, Fax: +49 441798194604 \\ Email: joerg.schorer@uol.de
}

\section{TA COMMENTARY}

\section{Article History:}

Received $17^{\text {th }}$ May 2016

Accepted $6^{\text {th }}$ June 2016

Published $13^{\text {th }}$ October 2016

Handling Editor:

Ernst-Joachim Hossner

University of Bern, Switzerland

Editor-in-Chief:

Martin Kopp

University of Innsbruck, Austria

\begin{abstract}
In this commentary on Joan Vicker's target article (2016), we first recognize the work she has done in the last 35 years. We then provide examples of differentiations of the Quiet Eye (QE) that might be necessary to fully understand the multifacetedness of the phenomenon. Here we propose, as in our current review (Rienhoff, Tirp, Strauss, Baker, \& Schorer, 2016), for the QE a differentiation by the mechanisms behind it. We suggest another categorization in the research on training the QE. Additionally, we provide further areas of research that are interesting for the future, namely the QE across life-span and the (in)dependence of the perceptual-motor processes.
\end{abstract}

Keywords:

perception - expertise - elite sport - motor behavior - learning - training

\section{Citation:}

Schorer, J., Tirp, J., \& Rienhoff, R. (2016). Quiet Eye: The next generation - comment on Vickers. Current Issues in Sport Science, 1:113. doi: 10.15203/ CISS_2016.113

This is a commentary on a CISS target article authored by Joan N. Vickers. For retrieving the whole target article including index of contents, editorial, main article, all peer commentaries and author's response:

Hossner, E.-J. (Ed.) (2016). Quiet Eye research - Joan Vickers on target. Current Issues in Sport Science, 1:100. doi: 10.15203/CISS_2016.100

\section{A recognizing introduction}

In her target article, Joan Vickers (2016) impressively summarizes 35 years of research starting with a practical perspective. Her discovery of the Quiet Eye (QE) as a perceptual motor phenomenon is an impressive accomplishment as is her pioneering work to bring the $\mathrm{QE}$ to the rising attention it has received in the last decades. She has published an impressive number of articles, brought this area of perceptual expertise to an interdisciplinary community and into the real world of applied coaching. Her fundamental research inspired many researchers around the world to investigate perceptual motor expertise and the specific phenomenon itself. For example, researchers have recently begun to look further at the mechanisms of the QE phenomenon (Rienhoff et al., 2016; S. Vine, Moore, \&Wilson, 2014). In this commentary, we provide examples of further de- lineations of the QE that might extend our understanding of the multifacetedness of this phenomenon and provide intriguing areas of future research.

\section{Differentiating eye-movements for QE categories}

To gain a deeper understanding of the way the QE works we might need to categorize and differentiate research on QE (Rienhoff et al., 2016). Vickers (2016) presents one by the tasks at hand. Recently, an ecological approach has been introduced by Rienhoff and colleagues (2016) to differentiate research on $\mathrm{QE}$. Another fruitful categorization might be to use a sensoryphysiological one. In her target article, Vickers presents studies in which either fixations (e.g.,Vickers, 1996) or smooth pursuit tracking (e.g.,Vickers \& Adolphe, 1997) are the dependent vari- 
ables, which are both summarized as QE. But necessarily one needs to differentiate between the functions of fixations and smooth pursuit eye tracking in visual perception (Holmqvist et al., 2011). The main difference is that a fixation is a position measurement and smooth pursuit tracking a movement measurement of a participant's gaze (Holmqvist et al., 2011). Concerning the QE research, duration (on-/ offset) and position measures are the main measurements. Investigating an eyemovement like smooth pursuit tracking enables to additionally measure directions, movement durations, velocities, accelerations and amplitudes (Holmqvist et al., 2011). These differences of two eye-behaviors might reflect the mechanisms behind the QE. For example, smooth pursuit tracking might be used to find an anchor for peripheral vision, while a fixation in an aiming task might be used to stabilize the movement system etc. This differentiation may be fruitful and we have begun a series of studies exploring these possibilities.

Future research might need to look at a combination of all of the possible categorization by perceptual processes or others to gain further insight. While the dependent variable might remain the QE as defined by Vickers (Vickers, 2007), single cells investigations of varying combinations might be necessary to explain mechanisms like the standing still hypothesis (Moore, Vine, Cooke, Ring, \& Wilson, 2012), which is related to postural stability and neuromuscular quiescence, the pre-programming hypothesis (Moore et al., 2012; Vickers, 2007; S. J. Vine \& Wilson, 2011), which associates the QE duration with a period of cognitive preprogramming of the movement, or the inhibition hypothesis (Klostermann, 2014) with a focus of explaining longer QE durations by an inhibition of alternative movement possibilities.

\section{Differentiating the needs of athletes in training}

As Vickers noted, a large number of studies have focused on the trainability of the QE (for an overview, S. Vine et al., 2014). Vickers (2016) classified a seven step QE training system on the basis of using QE prototypes of elite athletes. This approach is in line with research concerning motor performance, which assumes that there exists one 'optimal' technique for each sport (Irwin, Hanton, \& Kerwin, 2005; Jones, Bezodis, \& Thompson, 2009; Sherman, Sparrow, Jolley, \& Eldering, 2001). However, Cavanagh (1987) argued that performers in particular elite sports use a diversity of techniques with considerable deviation to achieve the same outcomes. Due to that assumption, future research needs to investigate whether performer-dependent QE training differences exist. It might well be, that QE training for novices has to be different to the type of training advanced athletes need to do.

Additionally, as will be argued below, some research (Tirp, Steingröver, Wattie, Baker, \& Schorer, 2015) has shown that perceptual and motor learning do not precede in parallel. In the context of QE training, it might be necessary to have a closer look at its impact on the motor result. Moreover, to gain deeper insight into the influence of $Q E$ training, one needs to consider the intervention duration necessary to obtain a positive effect in both QE duration and motor outcomes. Due to the fact that different interventions and instructions have been used in previous studies, future research should try to classify the training instructions to ensure a better comparability between different QE training studies.

\section{Perceptual-motor characteristics}

The $\mathrm{QE}$ is a phenomenon that looks by definition at perceptualmotor performances. An implicitly made assumption is that perceptual-motor learning precedes in parallel with the QE. Several studies have shown the trainability of the QE (for an overview, S. Vine et al., 2014); however, fewer studies have focused on the trainability of the QE and the motor result in association. Two studies which focused on the synchrony of perceptual-motor learning in real and virtual realities were done by Tirp and Schorer (in preparation) as well as by Tirp et al. (2015). Results indicated an asynchronous learning of perceptual and motor performance. Additionally, this does not imply the role of the cognitive system, which should not be under-estimated. For example, Castaneda and Gray (2007) postulated that a focus on skill executions positively affects motor learning processes. In the context of perceptual-motor learning, the focus of attention used by the performer might differ in either perceptual (e.g., QE) or motor learning (e.g., basketball free throw) parameters. Future research needs to integrate the cognitive with the perceptual and motor system in order to expand our knowledge in these key areas.

\section{Development and maintenance of QE in the life-span}

As Vickers (2016) proposed, the development of QE is an engaging area of research. Surprisingly, little has been done in the maintenance of QE as athletes' age. In a series of studies, Rienhoff et al. (2013) and Fischer et al., (2015) demonstrated that the role of $\mathrm{QE}$ in two different expertise groups and three different age groups might vary. In contrast to younger experts, showing the expected pattern of results, master athletes lose the $\mathrm{QE}$ and have shorter durations compared to novices in the same age group while still showing superior results. This is not only in contrast to younger age groups in QE (Rienhoff et al., 2016; Vickers, 2016), but also in contrast to previous findings on perceptual expertise in master athletes (Horton, Baker, \& Schorer, 2008; Schorer \& Baker, 2009). Together, these studies provide an interesting first step towards our understanding of the development of the QE phenomena across the lifespan, which might have implications not only for elite sports but also for everyday activities. 


\section{Conclusions}

The target article by Vickers (2016) nicely shows the amazing progress that has been made in this field of research. These first steps were important to describe the effect but future steps need to be more precise to cover the multifacetedness of the phenomena. This might only be possible by differentiating QE expertise research by the potential mechanisms behind it. Our current review provides some avenues to explore (Rienhoff et al., 2016), but there are certainly other perspectives that might be even more useful for gaining further insights into the QE. As another possible perspective, we propose the variation by categorizing the underlying eye-movement processes. The same line of argumentation holds for the current training research. A clear differentiation between levels of expertise of the learner might be needed to develop skill-adapted training programs. From our point of view, these differentiations are an important mission for the next generation.

\section{Acknowledgements}

We would like to express our gratitude for helpful comments by Joseph Baker on an earlier version of this paper. Additionally, we would like to thank Gene Roddenberry for the inspiration to think about the future.

\section{Funding}

The authors have no funding or support to report.

\section{Competing Interests}

The author has declared that no competing interests exist.

\section{Data Availability Statement}

All relevant data are within the paper.

\section{References}

Castaneda, B., \& Gray, R. (2007). Effects of focus of attention on baseball batting performance in players of differing skill levels. Journal of Sport \& Exercise Psychology, 29, 60-77.

Cavanagh, P. R. (1987). The cutting edge in biomechanics. In M. J. Safrit \& H. M. Eckert. (Eds.), The academy papers: The cutting edge in physical education and exercise science research (pp. 115119). Champaign, IL:Human Kinetics.

Fischer, L., Rienhoff, R., Tirp, J., Baker, J., Strauss, B., \& Schorer, J. (2015). Retention of quiet eye in older skilled basketball players. Journal of Motor Behavior, 47, 1-8. doi: 10.1080/00222895.2014.1003780
Holmqvist, K., Nyström, M., Andersson, R., Dewhurst, R., Jarodzka, H., \& van de Weijer, J. (2011). Eye tracking. A comprehensive guide to methods and measures (Vol. 1). Oxford, UK: Oxford University Press.

Horton, S., Baker, J., \& Schorer, J. (2008). Expertise and aging: Maintaining skills through the lifespan. European Review of Aging and Physical Activity, 5, 89-96. doi: 10.1007/s11556-008-0034-5

Irwin, G., Hanton, S., \& Kerwin, D. G. (2005). The conceptual process of skill progression development in artistic gymnastics. Journal of Sports Sciences, 23, 1089-1099. doi: 10.1080/02640410500130763

Jones, R., Bezodis, I., \& Thompson, A. (2009). Coaching sprinting: Expert coaches' perception of race phases and technical constructs. International Journal of Sports Science and Coaching, 4, 385-396.

Klostermann, A. (2014). Finale Fixationen, sportmotorische Leistung und eine Inhibitionshypothese: Mechanismen des "Quiet Eye" [Final fixations, motor performance, and an inhibition hypothesis: Mechanisms of the "quiet eye"]. Sportwissenschaft, 44, 49-59.

Moore, L. J., Vine, S. J., Cooke, A., Ring, C., \&Wilson, M. R. (2012). Quiet eye training expedites motor learning and aids performance under heightened anxiety: The roles of response programming and external attention. Psychophysiology, 49, 1005-1015.

Rienhoff, R., Hopwood, M. J., Fischer, L., Strauss, B., Baker, J., \& Schorer, J. (2013). Transfer of motor and perceptual skills from basketball to darts. Frontiers in Psychology, 4:593. doi: 10.3389/ fpsyg.2013.00593

Rienhoff, R., Tirp, J., Strauss, B., Baker, J., \& Schorer, J. (2016). The "quiet eye" and motor performance: A systematic review based on Newell's constraints-led model. Sports Medicine, 46, 589603. doi: 10.1007/s40279-015-0442-4

Schorer, J., \& Baker, J. (2009). An exploratory study of aging and perceptual-motor expertise in handball goalkeepers. Experimental Aging Research, 35, 1-19. doi: 10.1080/03610730802544641

Sherman, C. A., Sparrow, W. A., Jolley, D., \& Eldering, J. (2001). Coaches' perceptions of golf-swing kinematics. International Journal of Sport Psychology, 31, 257-270.

Tirp, J., \& Schorer, J. (2016). The visual sense makes the difference. Training of perception-specific focus of attention influences quiet eye duration but not throwing accuracy in darts. Unpublished manuscript.

Tirp, J., Steingröver, C., Wattie, N., Baker, J., \& Schorer, J. (2015). Virtual realities as optimal learning environments in sport. A transfer study of virtual and real dart throwing. Psychological Test and Assessment Modeling, 1, 57-69.

Vickers, J. N. (1996). Control of visual attention during the basketball free throw. American Journal of Sports Medicine, 24 (6th Suppl.), S93-S97.

Vickers, J. N. (2007). Perception, cognition, and decision training: The quiet eye in action. Champaign, IL: Human Kinetics.

Vickers, J. N. (2016). Origins and current issues in Quiet Eye research. Current Issues in Sport Science, 1:101. doi: 10.15203/ CISS_2016.101 
Vickers, J. N., \& Adolphe, R. (1997). Gaze behaviour during a ball tracking and aiming skill. International Journal of Sports Vision, 4, 18-27.

Vine, S. J., Moore, L. J., \& Wilson, M. R. (2014). Quiet eye training: The acquisition, refinement and resilient performance of targeting skills. European Journal of Sport Science, 14 (Suppl. 1), S235-242. doi: 10.1080/17461391.2012.683815

Vine, S. J., \& Wilson, M. R. (2011). The influence of quiet eye training and pressure on attention and visuo-motor control. Acta Psychologica, 136, 340-346. doi: 10.1016/j.actpsy.2010.12.008 